\title{
Nasal Cavity Neoplasm
}

National Cancer Institute

\section{Source}

National Cancer Institute. Nasal Cavity Neoplasm. NCI Thesaurus. Code C4413.

A benign or malignant neoplasm that affects the nasal cavity. Representative examples

of benign neoplasms include Schneiderian papilloma and salivary gland-type adenoma.

Representative examples of malignant neoplasms include carcinoma and lymphoma. 